\title{
A BIBLIOGRAFIA NO BRASIL SEGUNDO OS PRECEITOS OTLETIANOS: A LIDERANÇA DA BIBLIOTECA NACIONAL E OUTRAS AÇÕES
}

\section{LA BIBLIOGRAFÍA EN BRASIL DE ACUERDO CON LOS PRECEPTOS DE PAUL OTLET: EL LIDERAZGO DE LA BIBLIOTECA NACIONAL Y OTRAS ACCIONES}

\begin{abstract}
Carlos Henrique Juvêncio - carloshjuvsilva@yahoo.com.br Doutorando do Programa de Pós-graduação em Ciência da Informação da Universidade de Brasília (UnB). Professor na
\end{abstract}

UnB.

Georgete Medleg Rodrigues - medleg.georgete@gmail.com Doutora em História pela Université de Paris (Paris IVSorbonne). Professora da Universidade de Brasília (UnB).

\begin{abstract}
RESUMO
Introdução: Os ideais de Paul Otlet e Henri La Fontaine para a criação de uma grande fonte de informação perpassaram pela propaganda junto a governos, instituições e pessoas do mundo todo, as palavras de ordem eram Mundialismo, Internacionalismo e Universalismo. Nesse sentido, vários órgãos brasileiros aderem à proposta disseminada por meio do Instituto Internacional de Bibliografia por eles fundado em 1895.

Objetivo: Neste artigo objetivamos descrever algumas das ações no Brasil do início do século XX que foram ao encontro dos ideais da dupla belga.

Metodologia: A pesquisa foi desenvolvida utilizando documentos de arquivo, sobretudo os da Biblioteca Nacional, e publicações à época, notadamente bibliografias editadas por diferentes órgãos.

Resultados: Observa que instituições de relevo no contexto brasileiro se apropriaram do ideal Otletiano como, por exemplo, o Real Gabinete Português de Leitura, a Biblioteca Nacional e a Biblioteca da Marinha.

Conclusões: Conclui que grande parte das ações buscou enriquecer o Repertório Bibliográfico Universal e serviram como meio de propagação da CDU, mas que o maior ícone da influência dos Documentalistas no Brasil foi a Biblioteca Nacional, onde os preceitos de Otlet e La Fontaine influenciaram de forma mais profunda.
\end{abstract}

Palavras-chave: Bibliografia. Biblioteca Nacional. Documentação. Henri La Fontaine. Instituto Internacional de Bibliografia. Paul Otlet. 


\section{INTRODUÇÃO}

A fundação, em 1895, do Instituto Internacional de Bibliografia (IIB) em Bruxelas, Bélgica, é um marco; os ideais de Paul Otlet e Henri La Fontaine até hoje são alvo de estudos no mundo, suas ideias revolucionam a Biblioteconomia e dão um novo significado à Bibliografia. Amparados em ideais baseados na premissa de divulgação e compartilhamento de informações e entendendo que por meio do conhecimento o mundo alcançaria a paz, a dupla belga conclama instituições e pessoas a tomarem parte de suas ideias e ideais (OTLET; LA FONTAINE, 1895; RAYWARD, 1975).

Desta forma, como núcleo do projeto Mundaneum, que visava a criação de um grande centro mundial de confluência de informações e a possibilidade de trocas entre países, instituições e pessoas, a Bibliografia é utilizada como instrumento para a disseminação rápida de informações ao redor do mundo (RAYWARD, 1975).

Nesse sentido, nosso objetivo neste artigo é apontar algumas das iniciativas brasileiras que confluem e contribuem para que os ideais do Instituto sejam divulgados no país e que serviram, segundo nossa visão, como prelúdio para o estabelecimento da Documentação, enquanto disciplina, no país.

Assim, nossa revisão de literatura conta com textos de Otlet e La Fontaine (1895) e Otlet (1908), e seu principal biógrafo, Rayward (1975), além do Bulletin de L'Institut International de Bibliographie, donde buscamos depreender maiores informações sobre a vida e a obra de Paul Otlet e Henri La Fontaine. Sobremaneira, também buscamos obras de pesquisadores brasileiros que investigaram as relações estabelecidas entre personagens brasileiros e os belgas, sendo assim temos Fonseca (1957, 1973a, 1973b), Oddone (2006) e Ortega (2004, 2009a, 2009b), que nos fornecem pistas valiosas para a construção deste trabalho. 


\title{
2 OS IDEAIS OTLETIANOS DO INSTITUTO INTERNACIONAL DE BIBLIOGRAFIA
}

O Instituto Internacional de Bibliografia (IIB) foi fundado no ano de 1895, em Bruxelas, por ocasião do I Congresso Internacional de Bibliografia. Esse foi o primeiro evento internacional com o objetivo de tratar temas relacionados à organização da disciplina bibliográfica e seus métodos. Seus pais intelectuais, conforme já mencionado, foram a dupla de juristas belgas Paul Otlet e Henri La Fontaine (OTLET, 1908).

Segundo Otlet e La Fontaine (1895, p. 38), o Congresso decidiu pela/;

\begin{abstract}
1ำ Criação de um Instituto Bibliográfico internacional, que tem por objetivo os estudos das questões relativas à bibliografia em geral e, também, especialmente à elaboração do Repertório Universal. Este instituto decidirá sobre as unidades bibliográficas e tomará todas as medidas para a sua adoção por todas as partes interessadas: os cientistas, bibliotecários, editores e autores.

[...]

$3^{0}$ União Bibliográfica Internacional entre os governos que se comprometerem a tomar todas as medias necessárias ao registro regular dos livros e favorecer a elaboração do Repertório [Universal], assinando cópias na proporção de suas respectivas populações e sua produção literária anual (tradução nossa).
\end{abstract}

Assim, no primeiro número do Bulletin de L'Institut International de Bibliographie está publicado o estatuto do IIB, do qual podemos destacar os seguintes trechos:

I. - O Instituto internacional de Bibliografia é uma associação exclusivamente científica.

Visa:

1ํ Favorecer o progresso do inventário, da classificação e da descrição dos produtos do espírito humano.

[...]

$3^{0}$ dar assistência a qualquer tentativa séria de classificações internacionais.

$[\ldots]$ 
$5^{\circ}$ Contribuir, por meio de publicações e por quaisquer outros meios, para que aqueles que publicam, colecionam, analisam ou consultam livros ou outros produtos do espírito humano, adotem um sistema de classificação uniforme e internacional.

[...]

IV. - O Instituto escolherá seus membros efetivos dentre aquelas pessoas, instituições e associações que se ocupam verdadeiramente da bibliografia e biblioteconomia [...] (OTLET; LA FONTAINE, 1895, p. 12-14, tradução nossa).

Assim, o Instituto nasceu com a perspectiva de tornar acessível todo o registro de conhecimento produzido pela humanidade sob os preceitos da cooperação internacional. Para este fim utilizava a representação documental dos itens em fichas catalográficas padrão $7,5 \mathrm{~cm} \times 12,5 \mathrm{~cm}$ (formato de grande difusão até a criação dos catálogos on line). Cada ficha arrolava, conforme podemos ver na Figura 1, informações relativas à autoria da obra (Chauvin, Victor), título (Bibliographie des ouvrages arabes ou relatifs aux Arabes publiés dans l'Europe c hrétienne de 1810 à 1915, IV: Les Mille et une nuits), local, editora e data (Liège, H. Vaillant-Carmanne e 1900), número de páginas (228), número de classificação pela CDU (016: 398.2), entre outras coisas (OTLET, 1908).

Figura 1: Exemplo de ficha adotado no Repertório Bibliográfico Universal.

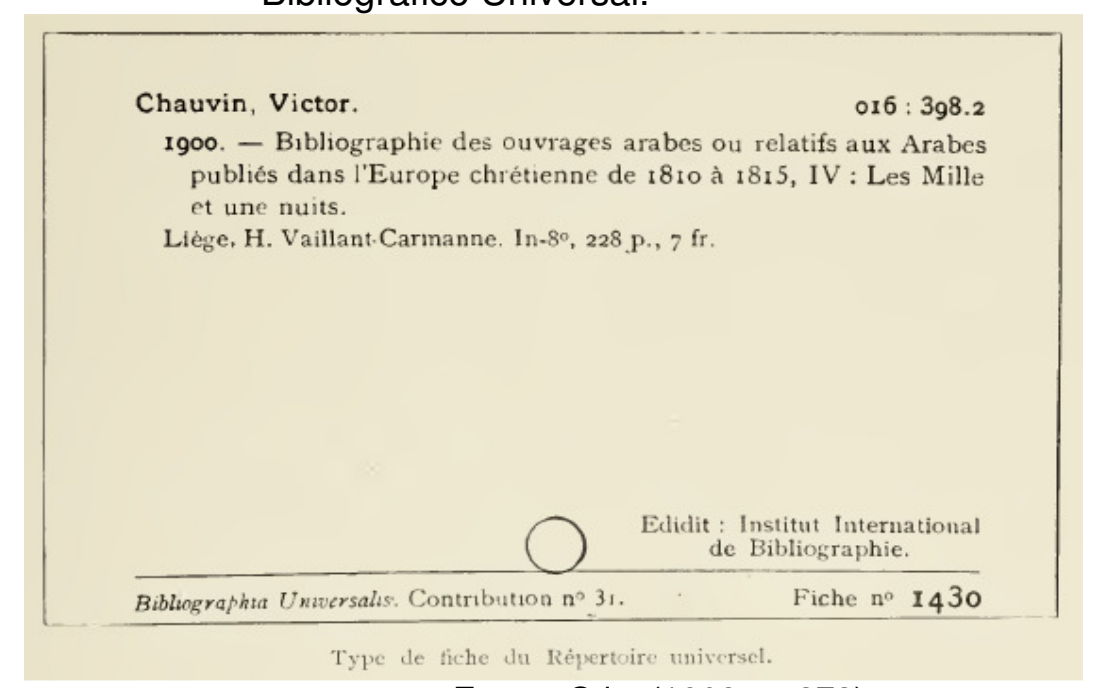

Fonte: Otlet (1908, p. 373). 
Tais fichas, por proposta do IIB, formavam o Repertório Bibliográfico Universal (RBU). Otlet (1908, p. 363-364) nos fala que:

\begin{abstract}
O objetivo deste repertório é coletar e manter constantemente atualizados elementos de um primeiro protótipo do repertório geral, reunindo registros bibliográficos relacionados com os escritos de qualquer natureza, cobrindo todos os assuntos publicados em todos os tempos e em todos os países. Para cada escrito (livros, artigos, memórias de sociedades científicas, publicações periódicas oficiais), uma descrição sinalética ou registro bibliográfico é feito. Esses registros são gravados em fichas móveis de formato único, $7,5 \mathrm{~cm} \times 12,5 \mathrm{~cm}$, cada um dos quais representa um único documento. Esses registros são armazenados em arquivos (tradução nossa).
\end{abstract}

O RBU, conforme descrito por Otlet (1908), buscava reunir em um único catálogo, através da representação documental, não só toda a produção intelectual humana já produzida, como também a que ainda seria realizada, por meio de sua constante atualização. Dessa forma, a construção do RBU seria um trabalho contínuo e sem fim, tendo em vista sua necessidade de constante atualização; ela contaria com a criação de Bibliografias Nacionais, por exemplo, outro instrumento de controle bibliográfico, que reúne toda a produção intelectual de determinado período (geralmente um ano) em determinada nação.

Apesar de a missão proposta para o RBU parecer utópica, ela diferia de outras tentativas de reunião de todo o conhecimento humano em um único local, como a Biblioteca de Alexandria, pois não consistia em reunir num único espaço toda a produção documental da humanidade, mas a sua representação.

Otlet e La Fontaine (1895) dizem que ao longo do século XIX, a importância da bibliografia havia crescido, tendo em vista os direitos conquistados pelo autor, a maior abertura das bibliotecas ao grande público e a necessidade de mecanismos de busca e recuperação da informação desejada, bem como de controle da produção intelectual por parte das editoras. Nesse sentido, os ideais do RBU têm por base os 
autores, os editores, as bibliotecas e seus usuários, os bibliotecários e os Estados.

Os autores, resguardados pela Convenção de Berna, que thes assegura o direito intelectual sobre suas criações, são posicionados como os espíritos por trás das grandes obras intelectuais humanas, passando a ser as figuras de destaque nos catálogos então organizados, também, onomasticamente. Já os editores, tradicionais criadores e difusores de bibliografias por causa de seus catálogos de venda, passaram a ser mais uma peça na intricada rede que Otlet e La Fontaine (1895) visavam criar.

As bibliotecas e seus usuários, como consumidores de bibliografias, ganharam uma posição de destaque nos ideais dos fundadores do IIB; a biblioteca, como local de consulta das mais variadas fontes de informação, era a instituição para a qual os esforços de cooperação na construção do RBU estavam voltados, buscando oferecer aos mais variados tipos de usuários uma espécie de enciclopédia mundial, na figura do repertório. Desta forma, seus usuários poderiam ter acesso a toda produção intelectual mundial, seja ela do passado ou do presente (OTLET; LA FONTAINE, 1895).

Já os bibliotecários são vistos por Otlet e La Fontaine (1895, p. 19) sob dois aspectos: os responsáveis por tornar públicos os "tesouros e preciosidades" presentes nos acervos das bibliotecas, fazendo-os, por meio de catálogos, acessíveis a todos, já que "[...] sem o catálogo a biblioteca é uma caixa fechada cheia de coisas preciosas, mas inacessível e invisível, sem chave" (OTLET; LA FONTAINE, 1895, p. 19); por outro lado, aos bibliotecários é confiada a construção das bibliografias, de modo a enriquecer o RBU.

Por fim, os Estados são descritos no projeto do RBU como os articuladores na criação de uma grande rede internacional para reunir a representação de todo o conhecimento humano, disponibilizando-a. Otlet e La Fontaine (1895) citam como exemplo as inciativas da França 
e da Alemanha, bem como a dos Estados Unidos, na construção de bibliografias nacionais em áreas específicas do conhecimento.

Sob estes pilares, os objetivos do RBU são formulados da seguinte maneira: $\left.1^{\circ}\right) \mathrm{O} \mathrm{RBU}$ deve ser completo, compreendendo a bibliografia do passado e do presente; $2^{\circ}$ ) A ordem do repertório deve ser tanto ideológica como onomástica, ou seja, tanto por assunto, quanto por autor; $3^{\circ}$ ) Como instrumento de pesquisa, o RBU deve estar disponível em todos os centros intelectuais; $4^{\circ}$ ) O RBU deve ser exato e preciso, mas deve também permitir a sua correção de modo simples e rápido; 5) O repertório deve estar totalmente disponível ao público; 6) O RBU deve estar associado a uma rede de catálogos de bibliotecas, permitindo o acesso rápido às obras; $7^{\circ}$ ) $A$ iniciativa deve servir de estatística intelectual acerca das obras produzidas pelo espírito humano; 8) O repertório deve assegurar aos autores a proteção legal de suas obras intelectuais (OTLET; LA FONTAINE, 1895, p. 16-17).

Objetivando cumprir a sua missão, o IIB adotou uma série de procedimentos para o tratamento dos itens que comporão o RBU; tal iniciativa visava a padronização universal de técnicas, bem como a coerência das representações. Com essa finalidade, o padrão americano de ficha, citado anteriormente, foi adotado, assim como a Classificação Decimal de Dewey (CDD) - criada em 1876 pelo bibliotecário americano Melvil Dewey -, instrumento de descrição temática dos itens no início do projeto.

Contudo, com o avanço dos trabalhos, Otlet e La Fontaine perceberam que a adoção da CDD não resolvia alguns problemas de classificação, muitos deles ficando sem solução. Nesse sentido, eles pedem autorização a Melvil Dewey para que a sua classificação seja adaptada aos ideais do Instituto e desta inciativa surge a Classificação Decimal Universal (CDU), que tem por propósito aperfeiçoar as formas de representação do conhecimento (RAYWARD, 1975).

Talvez a maior crítica de Otlet à CDD tenha sido quanto ao seu caráter restritivo, pois, como aponta Rayward (1975), esta classificação 
traz em seu escopo o modelo americano de ciência, privilegiando os Estados Unidos e seus aspectos no momento da classificação, resguardando várias classes ou assuntos apenas a esse país. Dessa forma, o resto do mundo, ou grande parte dele, é forçado a se adaptar em subclasses com números cada vez mais extensos e difíceis de serem localizados. Assim, a CDU explora todo o caráter que carrega em seu nome, buscando realmente ser uma classificação universal que permite a representação de todas as nações ou povos de forma quase igualitária, ou requerendo pequenas modificações (RAYWARD, 1975).

A CDU foi publicada por Otlet e La Fontaine entre os anos de 1904 e 1907 (RAYWARD, 1975). Hoje, após sofrer pequenas modificações, ela é ainda editada.

Em comparação à $C D D$, as classes principais da CDU são praticamente idênticas, porém, a Classificação de Dewey é organizada de forma decimal, com uso de ponto após a primeira sequência de três números, além de possuir a Classe 400 (Línguas). A maior diferença entre os dois sistemas de classificação parece residir no uso das tabelas auxiliares: a CDU é mais flexível quanto a isso, permitindo maior variedade de combinações e uso de símbolos, o que torna a descrição do item mais específica do que na CDD.

Aliada às técnicas de catalogação e descrição bibliográfica, a CDU passou a ser um instrumento pelo qual documentos que abordam o mesmo assunto ou assuntos correlatos podem ser encontrados mais facilmente, devido à aproximação forjada por catálogos sistemáticos.

\section{APROXIMAÇÕES ENTRE O INSTITUTO INTERNACIONAL DE BIBLIOGRAFIA E INSTITUIÇÕES BRASILEIRAS}

Fundado o Instituto, Otlet e La Fontaine passam a difundir seus ideais ao redor do mundo como meio de buscar adeptos à construção do repertório Bibliográfico Universal. Pois, conforme foi explicitado na seção anterior, a construção do RBU dependia da adoção de seu 
padrão por instituições e Estados dos diversos continentes. Nesse sentido, Fonseca (1973a, p. 40) nos fala que:

Quatro anos depois de fundado, o IIB contava com um membro brasileiro - Juliano Moreira - que utilizou a CDU na revista por ele dirigida: os Annaes da Sociedade de Medicina e Cirurgia da Bahia. Em 1900, outro grande cientista brasileiro introduzia o sistema na biblioteca do instituto que organizara e teve depois o seu nome: o Instituto Oswaldo Cruz. Em dezembro do mesmo ano, o engenheiro paulista Vítor Alves da Silva Freire - diplomado pela Escola Politécnica de Paris, Diretor de Obras Municipais e lente substituto da Escola Politécnica de São Paulo publicava em revista da mesma Escola um artigo sobre a necessidade da participação do Brasil na organização internacional da bibliografia científica* (grifo do autor).

Ortega (2009b) corrobora a informação dada por Fonseca (1973a), declarando que:

[...] [Víctor da Silva] Freire publicou um estudo sobre a CDU no Annuario da Escola Polytechnica de São Paulo, onde salientava a participação do Brasil na organização internacional da bibliografia científica. Este estudo foi publicado pelo IIB, no qual consta a informação de que a Livraria Civilização em São Paulo recebia assinaturas e encomendas de publicações do IIB e fornecia equipamentos e móveis por ele adotados.

Em seu texto, Freire (1901, p. 155) diz que:

O Office tem fornecido e continua a fornecer duplicatas do repertorio existentes a varias instituições; d'elle tira egualmente extractos referentes a questões especiaes, mediante insignificante retribuição.

Em resumo, a obra colossal e utilitaria que o Instituto tomou a seu cargo, acha-se em plena elaboração.

Optou-se, neste trabalho, por não fazer a atualização dos vocábulos das citações para as normas gramaticais e gráficas atuais. Entendemos que desta forma, mantemos a fidedignidade dos textos. 
Para a completa realisação do seu programma, dirige o Instituto um appello aos trabalhadores intellectuaes de todos os paizes.

Podemos nós, brasileiros, recusar-lhe a nossa cooperação?

$\mathrm{Na}$ America, depois dos Estados-Unidos, cuja parte em todo o movimento foi vista no decorrer da exposição, o Governo Mexicano, comprehendendo todo o interesse que havia no desenvolvimento da obra encetada, creou o Instituto Bibliographico Mejicano, instituição annexa á Bibliotheca Nacional, e cuja missão é reunir os elementos para a bibliographia geral do Mexico, abrangendo:

1. Todas as obras escriptas por Mexicanos, seja qual fôr o logar em que tenham sido publicadas;

2. - As obras de autores estrangeiros que tenham sido impressas no Mexico.

Que processo haverá, superior a este e de mais fecundos resultados, capaz de desvendar aos olhos de todos, nacionaies e estrangeiros, os recursos naturaes de um paiz novo e mal conhecido ou injustamente apreciado, o gráu de cultura e de civilisação dos seus filhos?

Realisar um tal objectivo equivale a collaborar para seu desenvolvimento, fortalecendo ao mesmo tempo o espirito de nacionalidade.

Portanto, sob este ponto de vista, não temos o direito de regatear no nosso auxilio á obra commum; cumprenos o dever de contribuir para o patrimonio da humanidade com a Bibliographia Brazileira.

E finaliza declarando que:

Com um pequeno esforço de cada um, a Bibliographia Brasileira será uma realidade dentro de pouco tempo.

A's [sic] corporações scientificas, ás escolas e academias, seria facil estabelecer, mediante insignificante despeza, duplicatas da Bibliographia Universal, que permittiriam pôr ao alcance do trabalhador as fontes de instrucção que tão grande falta hoje Ihe fazem.

Finalmente, a organisação racional das nossas bibliothecas transformal-as no que ellas devem ser: um instrumento de estudo ao alcance de todos (FREIRE, 1901, p. 156-157). 
Freire (1901) demonstra sua afinidade com a causa de Otlet e La Fontaine, enxergando a criação de fontes de informações como um meio para o desenvolvimento e para o progresso das nações.

Fonseca (1973a, p. 40) complementa essa gênese dos ideais bibliográficos no Brasil, afirmando que:

A Biblioteca da Câmara dos Deputados também está entre as primeiras do País que adotaram o catálogo sistemático segundo a CDU e receberam as publicações do IIB, graças à clarividência de seu diretor, que era, na época, o escritor Mário de Alencar (1872-1925), filho de José de Alencar e amigo íntimo de Machado de Assis.

Em 1902, a Biblioteca da Marinha (no Rio de Janeiro) também adere aos ideais do Instituto Internacional de Bibliografia. Silva (1902) observa que o bibliotecário João Augusto dos Santos Porto, ao iniciar a modernização da Biblioteca, opta por adotar a Classificação Decimal de Dewey pois:

Este importante systema de classificação é hoje adoptado pelo Instituto Internacional de Bibliographia, cuja missão é estabelecer um repertorio bibliographico universal pelo qual possa-se obter reproducções parciaes que tratem, respectivamente, de assumptos concernentes à quelquer ramo do conhecimento humano, de como a collocar sempre:

1. "Os homens de estudos ao corrente dos trabalhos de seus predecessores e de seus contemporaneos, para utilisar e levar mais longe as investigações scientificas evitando repetições involuntarias e perda de tempo.

2. "Os profissionaes, legisladores, adminstradores, etc., na posse de documentos que lhes possam ser uteis, fornecendo preciosos elementos de successos para as lutas industriaes ou na gestão dos negocios publicos.»

Com este objectivo procura o Instituto adoptar á esta classificação certos melhoramentos, de modo a preencher mais satisfactoriamente sua missão (SILVA, 1902, p. 905-906). 
Silva (1902) também observa que a Bibliografia, enquanto disciplina da Biblioteconomia, é elemento chave na organização do conhecimento humano, oferecendo preciosas informações sobre os livros. O que vai ao encontro aos ideais do IIB. Ademais, Silva (1902) realça que a gestão de empresas (sejam elas públicas ou privadas) pode ser melhorada se as informações estiverem organizadas e disponíveis de forma padronizada, oferecendo-nos uma visão sobre o caráter estratégico da informação também para o desenvolvimento econômico e a administração.

Outra instituição a tomar parte em tal ideal é o Real Gabinete Português de Leitura, cujo seu "Bibliothecário-Mór" era Benjamin Franklin Ramiz Galvão, promotor da grande reforma que a Biblioteca Nacional sofreu sob sua direção nas década de 1870 e 1880. Assim, ao publicar o Catalogo do Gabinete Português de Leitura no Rio de Janeiro, optou por organizar o:

[...] Catalogo segundo o systema decimal do illustre americano Melvil Dewey, acceito e preconizado pela Repartição Internacional de Bibliographia de Bruxellas, - systema que já adopataram mais de 1000 bibliothecas dos Estados Unidos e muitos dos conceituados especialistas do Velho-Mundo (RAMIZ GALVÃO, 1906, p. IX).

O bibliotecário continua sua "Advertencia" do Catalogo enumerando as vantagens do sistema de Melvil Dewey, destacando a aproximação física de obras que tratam de assuntos semelhantes, a padronização internacional da nomenclatura, ou seja, do número de chamada da obra, a sua criação por especialistas dentre outras (RAMIZ GALVÃO, 1906). Por fim, tece a seguinte consideração: "Parece que assim teremos contribuido para tornar util esta publicação, conservandoIhe entretanto perfeito accôrdo com os trabalhos do Instituto de Bruxellas, que préga com optimo fundamento as vantagens da 
uniformização bibliographica" (RAMIZ GALVÃO, 1906, p. XIII, grifo do autor).

Até que, em 1911, a Biblioteca Nacional brasileira lança as bases de seu Serviço de Bibliographia e Documentação, estabelecendo contato com o IIB por meio da figura de seu diretor, à época Manoel Cícero Peregrino da Silva. Fonseca (1957, p. 119) observa que:

[...] A Biblioteca Nacional teve a sorte de ser dirigida, de 1900 a 1915 e de 1919 a 1921, por Manoel Cícero Peregrino da Silva [...] Deve-se a êle, igualmente, a primeira tentativa de organização da bibliografia brasileira na base da cooperação nacional e internacional. Empolgado com as primeiras atividades do Instituto Internacional de Bibliografia, de Bruxelas, Manoel Cícero Peregrino da Silva compreendeu logo o que Fidelino de Figueiredo diria mais tarde, na primeira de suas memoráveis conferências em São Paulo: "o serviço bibliográfico já não pode ser devoção individual, nem fantasia acadêmica, tem de ser desempenhado por um organismo técnico, um Instituto Nacional de Bibliografia com pessoal especializado, com a estreita colaboração das bibliotecas e hemerotecas, não para publicar um Dicionário Bibliográfico, mas, para organizar a bibliografia geral do passado e registrar a de cada dia e cada hora". Na reforma que introduziu na Biblioteca Nacional em 1911, Manoel Cícero Peregrino da Silva estabeleceu um "Serviço de Bibliografia e Documentação em correspondência com o Instituto Internacional de Bibliografia de Bruxelas". [...] Por aí se vê que Manoel Cícero Peregrino da Silva foi também precursor em matéria de serviços bibliográficos e que na sua reforma da Biblioteca Nacional estava quase profèticamente anunciando o órgão que só em 1954 se instalaria, com o nome de Instituto Brasileiro de Bibliografia e Documentação.

Desta forma, Peregrino da Silva justifica a adesão da Biblioteca ao ideal do Instituto declarando em seu relatório de 1909 (SILVA, 1910) que a Bibliografia seria o elemento chave na organização do conhecimento humano, servindo de norte para a descrição dos documentos, entendendo que: 
A documentação no sentido amplo que the atribue o Instituto [Internacional de Bibliografia] abrange não só os textos manuscriptos e impressos, mas tudo quanto se tem empregado como meio de realisação da produção intellectual e como meio de transmissão das acquisições do homem no dominio da intelligencia. É a reunião e a coordenação de todos os documentos, conjucto que representará a experiencia universal (SILVA, 1910, p. 773).

Peregrino da Silva ainda prossegue, dizendo que "[...] A documentação vem coordenar os elementos caracteristicos dos materiaes que a intelligencia humana vae accumulando atravez dos seculos" (SILVA, 1910, p. 773).

Tais ideias parecem indicar a afinidade de seu pensamento com o de Paul Otlet e Henri La Fontaine, sob este prisma, Fonseca (1957, p. 98) declara que "Manoel Cícero Peregrino da Silva foi um autêntico precursor brasileiro da Documentação, um homem com visão profética de Paul Otlet e Henri La Fontaine". Fonseca (1973a, p. 41) chega a nomear Peregrino da Silva de Otlet brasileiro.

Ortega (2004, p. 6), por exemplo, destaca que:

[...] em 1911, o professor de Direito Manoel Cícero Pelegrino [sic] da Silva, diretor-geral da Biblioteca Nacional, no Rio de Janeiro, criou o Serviço de Bibliografia e Documentação em correspondência com - IIB, com a pretensão de organizar o repertório bibliográfico brasileiro em fichas catalográficas e com uso da CDU, incluindo o tratamento dos artigos de periódicos, como uma contribuição ao controle bibliográfico internacional.

Oddone (2006, p. 47), por sua vez, observa que:

Disponível na literatura brasileira da área desde os trabalhos produzidos por Edson Nery da Fonseca na década de 1950, a ligação entre a Documentação e Biblioteconomia nos conduzia diretamente à figura de Manuel Cícero Peregrino da Silva e às iniciativas por ele implementadas na Biblioteca Nacional durante os anos de 1910 e 1920, traços seguros da entrada do conceito de Documentação no país e da nossa participação no movimento europeu liderado por Paul 
Otlet (FONSECA, 1957, 1973; RAYWARD, 1996). (ODDONE, 2010, p.4-5).

Nesse sentido, podemos observar que algumas ações de instituições e/ou brasileiros foram de encontro aos ideais do Instituto Internacional de Bibliografia, mas que em tal cenário a Biblioteca Nacional se destaca.

Inicialmente, se pensarmos em termos de construção do RBU, a edição da Bibliografia Brasileira sob o título "Boletim Bibliographico da Bibliotheca Nacional do Rio de Janeiro" é o de mais representativo dentre suas ações.

Tal Boletim, organizado segundo os preceitos ditados pelo IIB, foi preparado por Cícero de Britto Galvão, funcionário da Biblioteca que foi mandado à Bruxelas, em 1913, afim de apreender as técnicas utilizadas pelo Instituto na construção do repertório Bibliográfico Universal (MAGALHÃES, 1918).

Contudo, também podemos destacar a aprovação da Lei de Depósito Legal em 1907 que garantia o recebimento das obras editadas em todo o país e não somente no Distrito Federal; a adesão, em 1909, à Convenção da União de Berna, que objetiva proteção dos direitos intelectuais sobre obras literárias e artísticas; a criação em 1911 do Serviço de Bibliographia e Documentação que visava, dentre outras ações, o ser um dos correspondentes do IIB no mundo, editar a Bibliografia brasileira, comprar fichas do RBU e torna-las disponíveis ao público; além da criação do curso de Biblioteconomia, também em 1911, que visava formar funcionários aptos ao trabalho na Biblioteca (JUVÊNCIO, 2014).

Sobre o Serviço de Bibliographia e Documentação, é importante destacar que ele deriva das conversas e negociações iniciadas em 1907 por ocasião da visita de Peregrino da Silva ao Instituto Internacional de Bibliografia, sendo construído de acordo com as premissas da instituição belga. Seu regulamentos traz os seguintes dados: 
Art. 137. O serviço de bibliographia e documentação, em correspondencia com o do Instituto Internacional de Bibliographia de Bruxellas, abrangerá:

$1^{\circ}$, a organização, segundo o systema de classificação decimal e por meio de fichas, do repertorio bibliographico brasileiro como contribuição para 0 repertorio bibliographico universal, de modo a comprehender as obras de autores nacionaes ou estrangeiros, impressas ou editadas no paiz, as de autores nacionaes, impressas no estrangeiro ou ineditas e as de autores estrangeiras que se occuparem especialmente do Brazil, incluidos os artigos insertos em publicações periodicas e os escriptos de qualquer natureza;

$2^{\circ}$, a impressão dessas fichas para serem expostas á venda ou permutadas por fichas de repertorios estrangeiros;

$3^{\circ}$, a acquisição de um exemplar de cada uma das fichas que constituem os repertorios estrangeiros, já organizados e que se forem organizando;

4ํㅡ, a cooperação da Bibliotheca na organização do repertorio-encyclopedico universal;

5o, a organização do catalogo collectivo das bibliothecas brazileiras;

$6^{\circ}$, o uso publico dos repertorios e do catalogo collectivo (BRASIL, 1911).

Estando, dessa forma, totalmente alinhado aos ideais do IIB.

Já o curso de Biblioteconomia traz dentre as matérias ministradas a bibliografia, mas parece-nos que a bibliografia propagada por Paul Otlet e Henri La Fontaine, pois, segundo indicam nossas pesquisas, o escopo da disciplina trazia o ensino da:

6ํㅡㄹ Classificação - sistemas principais.

$7^{0}$ Classificação decimal. Suas modificações.

[...]

9 A catalogação. Catalogos. A ficha. Arrumação dos livros e preparo para catalogação.

$10^{\circ}$ O Catalogo. Fontes de informação. Repertorio (ALVES, 1916).

Desta forma, a Biblioteca Nacional visava forma profissionais familiarizados com os serviços oferecidos por esta, incluindo aqueles que têm relação direta com os ideais de Paul Otlet e Henri La Fontaine. 
Decerto, a BN cumpria à risca as diretrizes do IIB e se comprometera com seus ideais.

\section{CONSIDERAÇÕES FINAIS}

As ações apontadas na seção anterior nos permitem verificar que as instituições brasileiras e seus agentes (bibliotecários, diretores etc) adotaram os ideais do Instituto Internacional de Bibliografia como seus. Contudo, com exceção à Biblioteca Nacional, tais inciativas se fixaram apenas na adoção da Classificação Decimal de Dewey (e, posteriormente a Classificação Decimal Universal) como forma de organização das obras e dos catálogos, bem como a edição de bibliografias.

Este fato ocorre com a Biblioteca da Marinha e com o Real Gabinete Português de Leitura, ambos no Rio de Janeiro, assim como na Escola Polytechnica de São Paulo e na Sociedade de Medicina e Cirurgia da Bahia, apontados por Ortega (2009b) e Fonseca (1973a).

A única instituição que parece ir além é a Biblioteca Nacional que funda o seu Serviço de Bibliographia e Documentação em correspondência com o IIB; compra fichas do Repertório Bibliográfico Universal; funda um curso de Biblioteconomia; adota a Documentação como preceito para o tratamento de seus acervos, bem como enxerga na Bibliografia um meio de controle e divulgação da produção intelectual brasileira. Outra ação é a edição do Boletim Bibliographico da Bibliotheca Nacional entre 1918 e 1921, fruto do envio de um funcionário da instituição à Bruxelas para estudar os modos de organização do IIB (JUVÊNCIO, 2014).

Por fim, nos parece que um ensaio de movimento bibliográfico brasileiro acontece no período, mas sem a coordenação necessária para que realmente se efetivasse. 


\section{REFERÊNCIAS}

ALVES, Constâncio. Pontos para as provas de Bibliografia [para o curso de Biblioteconomia da Biblioteca Nacional]. Rio de Janeiro, dez. 1916.04 doc. (5 p.). Original. Manuscrito. (Serie Curso de

Biblioteconomia. Coleção Biblioteca Nacional. Loc.: 66,1,003 no 033).

BRASIL. Decreto no 8.835, de 11 de julho de 1911. Approva o regulamento da Bibliotheca Nacional. Diário Oficial da União, Brasília, D. F., 16 jul. 1911. Disponível em:

$<$ http://www2.camara.leg.br/legin/fed/decret/1910-1919/decreto-8835-11julho-1911-502890-republicacao-102224-pe.html>. Acesso em: 23 maio 2012.

FONSECA, Edson Nery da. Desenvolvimento da Biblioteconomia e da Bibliografia no Brasil. Revista do Livro, Rio de Janeiro, v. 2, n. 5, p. 95124, mar. 1957.

. Origem, evolução e estado atual dos serviços de documentação

no Brasil. Revista do Serviço Público, Brasília, v. 108, n. 1, p. 37-52, jan./abr. 1973a.

Bibliografia estatística e bibliometria: uma reivindicação de prioridades. Ciência da Informação, Rio de Janeiro, v. 2, n. 1, p. 5-7, 1973b.

FREIRE, Victor da Silva. A bibliographia universal e a classificação decimal. Annuario da Escola Polytechnica de São Paulo, São Paulo, n. 2, p. 125-157, 1901.

JUVÊNCIO, Carlos Henrique. O Mundaneum no Brasil: o serviço de bibliographia e documentação da Biblioteca Nacional e seu papel na implementação de uma rede de informações científicas. 2014. $190 \mathrm{f}$. Dissertação (Mestrado em Ciência da Informação) - Universidade de Brasília, Brasília, 2014.

MAGALHÃES, Basílio de. Prefácio. Boletim bibliographico da Bibliotheca Nacional do Rio de Janeiro, Rio de Janeiro, v. 1, n. 1, jan./mar. 1918.

ODDONE, Nanci. A documentação no brasil e seu impacto durante o estado novo. In: ENCONTRO NACIONAL DE PESQUISA EM CIÊNCIA DA INFORMAÇÃO, 11., 2010, Rio de Janeiro. Anais... Rio de Janeiro, 2010. Disponível em:

<http://enancib.ibict.br/index.php/enancib/xienancib/paper/viewFile/3399/ 2525>. Acesso em: 15 mar. 2014. 
- O IBBD e a informação científica: uma perspectiva histórica para a ciência da informação no Brasil. Ciência da Informação, Brasília, v. 35, n. 1, p. 45-56, jan./abr. 2006.

ORTEGA, Cristina Dotta. Relações históricas entre biblioteconomia, documentação e ciência da informação. DataGramaZero: Revista de Ciência da Informação, Rio de Janeiro, v. 5, n. 5, out. 2004.

A documentação como uma das origens da ciência da informação e base fértil para sua fundamentação. Brazilian Journal of Information Science, Marília, v. 3, n. 1, p. 3-35, jan./jun. 2009a.

. Surgimento e consolidação da Documentação: subsídios para compreensão da história da Ciência da Informação no Brasil.

Perspectivas em Ciência da Informação, Belo Horizonte, v. 14, n. especial, p. 59-79, 2009b.

OTLET, Paul. L'Office international de bibliographie. In: OVERBERGH, Cyrille. Le Mouvement scientifique en Belgique: 1830-1905: tomo II. Bruxelas: Société Belge de Librairie, p. 358-374, 1908. Disponível em: <http://ia701200.us.archive.org/1/ items/lemouvementscien02over/lemouvementscien02over.pdf $>$. Acesso em: 13 jan. 2012.

OTLET, Paul; LA FONTAINE, Henri. Création d'un répertoire bibliographique universel: note préliminaire. Bulletin de L'Institut International de Bibliographie, La Haye, v. 1, n. 1, p. 15-38, 1895.

GALVÃO, Benjamin Franklin Ramiz. Catálogo do gabinete português de leitura no Rio de Janeiro. Rio de Janeiro: Typ. do "Jornal do Commercio" de Rodrigues \& C., 1906. v. 1.

RAYWARD, W. Boyd. The universe of information: the work of Paul Otlet for documentation and international organization. Moscow: VINITI, 1975.

SILVA, Mario R. da. A catalogação decimal da bibliotheca de Marinha. Revista Marítima Brasileira, Rio de Janeiro, v. 21, n. 7, p. 891-911, jan. 1902.

SILVA, Manoel Cícero Peregrino da. Annaes da Bibliotheca Nacional do Rio de Janeiro, v. 32, p. 746-774, 1910. Disponível em: <http://objdigital.bn.br/acervo_digital/anais/anais_032_1910.pdf>. Acceso em: 15 ago. 2014. 
Carlos Henrique Juvêncio; Georgete Medleg Rodrigues

A bibliografia no Brasil segundo os preceitos otletianos: a liderança da

Biblioteca Nacional e outras ações

\section{Title}

The bibliography in Brazil according to Otlet's precepts: the leadership of the National Library and other actions

\section{Abstract}

Introduction: The ideals of Paul Otlet and Henri La Fontaine to create a great source of information permeated by advertising with governments, institutions and individuals around the world, the slogans were globalism, internationalism and universalism. Several Brazilian agencies adhere to the proposal disseminated through the International Institute of Bibliography, by them founded in 1895

Objective: In this article we describe some of the actions in Brazil of the early twentieth century that were to meet the ideals of the belgian duo.

Methodology: The research was conducted using archival documents, especially National Library documents, and publications at the time, notably bibliographies published by different agencies.

Results: Notes that relevant institutions in the Brazilian context appropriated the ideal of Paul Otlet, for example, the Royal Portuguese Reading Room, the National Library and the Marine Library.

Conclusions: Concludes that much of the action sought to enrich the Universal Bibliographic Repertory and served as a means of spreading the CDU, but the greatest icon of the influence of Documentalists in Brazil was the National Library, where the precepts of Otlet and La Fontaine influenced more deeply.

Keywords: Bibliography. Documentation. Henri La Fontaine. International Institute of Bibliography. National Library. Paul Otlet.

\section{Titulo}

La bibliografía en Brasil de acuerdo con los preceptos de Paul Otlet: la liderazgo de la Biblioteca Nacional y otras acciones

\section{Resumen}

Introducción: Los ideales de Paul Otlet y Henri La Fontaine para crear una gran fuente de información fueron difundidos a través de publicidad junto a gobiernos, instituciones e individuos de todo el mundo. Las consignas de este proyecto eran globalismo, internacionalismo y universalismo. En este sentido, varios organismos brasileños adhirieron a la propuesta diseminada por medio del Instituto Internacional de Bibliografía creado por Otlet e La Fontaine en 1895.

Objetivo: En este artículo se describen algunas de las acciones en Brasil, de principios del siglo XX, las cuales han convergido con los ideales mencionados. Metodología: La investigación se realizó utilizando documentos de archivo, especialmente los de la Biblioteca Nacional, y publicaciones de la época, en particular bibliografías publicadas por distintos organismos.

Resultados: Notas que instituciones pertinentes en el contexto brasileño se 
apropiaron de el ideal de Paul Otlet, por ejemplo, la Real Portugués Sala de Lectura, la Biblioteca Nacional y la Biblioteca de Marina.

Conclusiones: Concluye que gran parte de la acción trató de enriquecer el Repertorio Bibliográfico Universal, y sirvió como medio de difusión de la CDU. Sin embargo, lo más grande signo de la influencia de Otlet y La Fontaine en Brasil fue la Biblioteca Nacional, adonde los preceptos de estos personajes fueron aceptados y adoptados, resultando en la creación de un servicio bibliográfico en ámbito nacional.

Palabras clave: Bibliografía. Biblioteca Nacional. Documentación. Henri La Fontaine. Instituto Internacional de Bibliografía. Paul Otlet.

Recebido em: Abril de 2015

Aceito em: Julho de 2015 